\title{
Substrato e solução nutritiva desenvolvidos a partir de efluente de biodigestor para cultivo do meloeiro
}

\author{
Luiz V. E. Villela Jr. ${ }^{1}$, Jairo A. C. de Araújo ${ }^{2}$, José C. Barbosa ${ }^{3}$ \& Luiz R.B. Perez ${ }^{4}$
}

\begin{abstract}
RESUMO
Buscando a sustentabilidade em uma pequena propriedade agrícola visou-se com o presente estudo, ao aproveitamento do efluente de biodigestor proveniente da fermentação anaeróbia de estrume bovino, no cultivo sem solo do meloeiro. O experimento foi conduzido em Jaboticabal, SP, Brasil, localizado na Latitude $21^{\circ} 15^{\prime} 22^{\prime \prime}$ S e Longitude $48^{\circ} 18^{\prime}$ 58 " W. Cultivouse o meloeiro (Cucumis melo L. cv. Bonus $n^{\circ}$ 2) em substrato, com semeadura realizada em outubro de 2003 e se utilizou delineamento experimental em blocos casualisados com 16 tratamentos e 5 repetições, em esquema fatorial $4 \times 4$ ( 4 substratos e 4 soluções nutritivas). Os 4 substratos se compunham de diferentes proporções da mistura entre a parte sólida do efluente de biodigestor e a areia grossa lavada; as 4 soluções nutritivas foram compostas pela parte líquida do efluente de biodigestor (biofertilizante) em substituição a adubos minerais hidrossolúveis. A adição do efluente à areia proporcionou crescimento vegetativo mais rápido, maior precocidade na colheita, frutos mais pesados e maior produtividade à cultura do meloeiro. Adubos minerais hidrossolúveis utilizados no cultivo de plantas em substrato podem ser parcialmente substituídos pelo biofertilizante estudado.
\end{abstract}

Palavras-chave: hidroponia, Cucumis melo L., biofertilizante, aproveitamento de resíduo

\section{Substrate and nutrient solution developed using a biodigestor effluent for melon cultivation}

\begin{abstract}
Looking for the sustainability of a small farming enterprise, the present study focused the benefit of the biodigestor effluent resulting from the anaerobic fermentation of the bovine manure in a soilless melon plant experiment. The research was conducted in Jaboticabal, in the State of Sao Paulo, Brazil, at latitude of $21^{\circ} 15^{\prime} 22^{\prime \prime} \mathrm{S}$ and a longitude of $48^{\circ} 18^{\prime} 58^{\prime \prime} \mathrm{W}$. The melon plant (Cucumis melo L. cv Bonus $n^{\circ}{ }^{2}$ ) was grown with substrate, seedling obtained in 10/2003. An experimental design was adapted in a randomized block with 16 treatments and 5 replications in a factorial $4 \times 4$ ( 4 substrates and 4 nutrient solutions). The 4 substrates were made up of different proportions in volume of the blend composition taking into consideration both the solid part of the biodigestor effluent and the washed raw sand. The 4 nutrient solutions were made up of the liquid part of the biodigestor effluent (biofertilizer) in substitution to the mineral water soluble fertilizers. The addition of the effluent in the sand led to a more rapid vegetative growth, a more precoceous crop with heavier fruits and a much better yield of melon crop. The mineral water soluble fertilizers used in the cultivation of plants in substrates can be partially replaced by the biofertilizer studied.
\end{abstract}

Key words: hydroponics, Cucumis melo L, biofertilizer, reutilization of residue

\footnotetext{
Doutorando em Agronomia pelo Programa de Pós-Graduação em Produção Vegetal da FCAV/UNESP. Via de Acesso Prof. Paulo Donato Castellane s/n., CEP 14884-900, Jaboticabal, SP. Fone: (16) 3209 2637. E-mail: villelajunior@yahoo.com.br

2 DER/UNESP. E-mail: jaca@fcav.unesp.br

${ }^{3}$ Depto. Ciências Exatas/UNESP. Fone: (16) 3209 2624. E-mail: jcbarbosa@fcav.unesp.br

${ }^{4}$ Depto. de Produção Industrial/FATEC. Av. Dr. Flávio Henrique Lemos n. 585, Portal Itamaracá, CEP 15900-000. Taquaritinga/SP. Fone: (16) 32525250.

E-mail: bayonaperez@yahoo.com.br
} 


\section{INTRODUÇÃO}

As mudanças conceituais por que passa a sociedade moderna, levam a se repensar os atuais modelos predominantes de produção de alimentos. Indubitavelmente, tais modelos desperdiçam recursos internos e externos da propriedade agrícola, como energia, água, fertilizantes e agrotóxicos, entrando em conflito com as dimensões sociais, econômicas e ambientais, responsáveis pela sustentabilidade dos agrossistemas (Menezes Júnior et al., 2004).

O cultivo sem solo surgiu como uma técnica altamente racional, buscando-se uma otimização no uso da água, do espaço, do tempo, dos nutrientes e da mão-de-obra (Castellane \& Araújo, 1994).

Com o passar do tempo, desenvolveram-se algumas variantes do cultivo sem solo, entre as quais se destaca, como sendo muito utilizado, o cultivo em substratos. Quanto à composição de substratos de cultivo, Kämpf (2000) afirma que dificilmente se encontra, na natureza, um material que, por si só, atenda a todas as exigências de um substrato ideal. Desta forma, são feitas misturas com condicionadores, que promovem a melhoria em uma ou mais propriedades do material original. Entre os condicionadores mais usados está a areia, que serve para melhorar não só a densidade mas, também, a drenagem dos substratos. Abad \& Nogueira (1998) consideram favorável a mistura de materiais de origem orgânica com materiais minerais de origem natural ou artificial, como areia, perlita, vermiculita e poliestireno expandido. Um dos fatores mais importantes na escolha de matérias-primas utilizadas na composição de um substrato é, indubitavelmente, o fator ambiental, devendo-se escolher materiais abundantes e renováveis, procurando-se diminuir o impacto desta prática no meio ambiente. Deste modo, recomenda-se a utilização de resíduos agrícolas da própria propriedade, pois assim se estará contribuindo para a busca da sustentabilidade em uma empresa agrícola, através da manutenção dos recursos naturais de uma propriedade, da minimização de impactos adversos e da otimização da produção com mínimo de insumos externos. Dentro desta filosofia agroecológica, muitas pesquisas vêm sendo realizadas com o objetivo de avaliar a utilização de resíduos agroindustriais na composição de substratos de cultivo.

$\mathrm{O}$ uso indiscriminado de fertilizantes minerais, tanto em sistemas convencionais de cultivo quanto em sistemas de cultivo sem solo, pode causar sérios danos ao meio ambiente e provocar uma escassez precoce de muitas reservas naturais de alguns nutrientes para a agricultura. Segundo Menezes Júnior et al. (2004) o emprego de insumos de origem orgânica, como biofertilizantes, na formulação de soluções nutritivas para cultivo sem solo, pode ser uma técnica viável. Seguindo este pensamento, Mavrogianopoulos et al. (2002) conseguiram respostas positivas, tanto no crescimento quanto na produção de biomassa de "cana gigante" (Arundo donax L.) utilizando, como solução nutritiva, esgoto proveniente de uma granja de suínos.

Segundo Bryant (1979) e Bungay (1981), apud por Fries \& Aita (1990), efluentes oriundos de biodigestor apresentam características distintas em relação ao material original (antes da biodegradação). Chaves (1977) afirmou que esses efluentes podem servir de fertilizantes agrícolas, alimento para animais e acondicionantes para o solo. Chaves (1981) evidencia que os efluentes de biodigestores apresentam nutrientes mais facilmente absorvíveis pelas plantas, quando comparados com o material orgânico antes do processo de biodigestão. $\mathrm{Na}$ Rússia, Nikmane et al. (1990) concluíram que soluções nutritivas à base de esterco suíno, fermentado anaerobiamente, podem substituir soluções nutritivas à base de sais minerais na produção hidropônica de forrageiras. No Brasil, Villela Júnior et al. (2003) demonstraram que a substituição parcial de adubos minerais por biofertilizante produzido com efluente de biodigestor mostrou-se viável no cultivo do meloeiro em sistema hidropônico aberto com substrato. Dentro desse enfoque objetivou-se, com a presente pesquisa, a contribuição para a sustentabilidade de uma pequena propriedade agrícola através da utilização de efluente de biodigestor como matéria-prima para composição de substratos de cultivo e de soluções nutritivas para o cultivo sem solo do meloeiro.

\section{MATERIAL E MÉTODOS}

O ensaio foi instalado no Setor de Plasticultura do Departamento de Engenharia Rural da FCAV/UNESP - Campus de Jaboticabal, localizado na latitude $21^{\circ} 15^{\prime} 22^{\prime \prime} \mathrm{S}$ e longitude $48^{\circ} 18^{\prime} 58^{\prime \prime} \mathrm{W}$, com altitude média de $575 \mathrm{~m}$. O clima da região, segundo classificação de Köppen, é do tipo Cwa, subtropical, relativamente seco no inverno, com chuvas no verão, apresentando temperatura média anual de $22{ }^{\circ} \mathrm{C}$ e precipitação média anual de 1552 mm (Volpe et al., 1989).

Definiram-se 16 tratamentos constituídos pelas combinações de 4 substratos de cultivo e 4 soluções nutritivas. Os 4 substratos foram formados pela mistura entre a parte sólida do efluente de biodigestor e areia grossa lavada, nas seguintes proporções em volume: substrato $1(\mathrm{~S} 1)=3 / 4$ efluente sólido $+1 / 4$ areia grossa lavada; substrato $2(\mathrm{~S} 2)=1 / 2$ efluente sólido $+1 / 2$ areia grossa lavada; substrato $3(\mathrm{~S} 3)=1 / 4$ efluente sólido $+3 / 4$ areia grossa lavada e substrato $4(\mathrm{~S} 4)=100 \%$ areia grossa lavada.

Para formulação das 4 soluções nutritivas utilizou-se do biofertilizante (parte líquida do efluente) complementado com adubos minerais industrializados, exceção feita à solução nutritiva 4 , em que foram utilizados apenas fertilizantes minerais industrializados; a seguir, encontram-se descritas as soluções nutritivas utilizadas na presente pesquisa: solução nutritiva 1 (SN1) = organo-mineral com $100 \%$ do nitrogênio total proveniente do biofertilizante; solução nutritiva 2 (SN2) = organo-mineral com $2 / 3$ do nitrogênio total proveniente do biofertilizante; solução nutritiva $(\mathrm{SN} 3)$ = organo-mineral com $1 / 3$ do nitrogênio total proveniente do biofertilizante e solução nutritiva $(\mathrm{SN} 4)=100 \%$ mineral, composta somente por fertilizantes minerais hidrossolúveis.

Para obtenção do substrato de cultivo e do biofertilizante, utilizaram-se as partes sólida e líquida, respectivamente, provenientes da separação do efluente de origem bovina processado em um biodigestor modelo indiano o qual, por sua vez, foi operado com cargas diárias, sendo que cada carga repre- 
sentou volume de 110 L, implicando em tempo de retenção de 50 dias. O efluente foi coletado e separado em partes sólida e líquida, por processo de decantação; logo após, a parte líquida foi armazenada em um tanque para posterior utilização como biofertilizante, enquanto a parte sólida foi secada ao sol para posterior elaboração dos substratos.

Depois de secado ao sol, o material sólido foi moído e as misturas foram feitas com as diferentes proporções em volume, de areia grossa lavada, definidas para cada substrato; assim, buscou-se obter a melhor proporção da mistura, através da variação das características físico-químicas do substrato, procurando-se obter uma drenagem melhor do excesso de solução nutritiva e/ou uma aeração melhor do sistema radicular, seguindo recomendações de Abad \& Nogueira (1998).

Quanto aos tratamentos em que se utilizou a solução nutritiva SN4 (100\% mineral) empregou-se a solução nutritiva proposta por Castellane \& Araújo (1994) para a cultura do meloeiro, com: 167,15; 39,10; 222,12; 153,00; 24,60; 35,72; 2,00; 0,66; 0,21; 0,25; 0,02 e 0,05 mg de N, P, K, Ca, Mg, S, Fe, Mn, $\mathrm{B}, \mathrm{Zn}, \mathrm{Cu}$ e Mo, por litro de solução nutritiva, respectivamente.

Em relação à formulação das soluções nutritivas organominerais (SN1, SN2 e SN3) coletaram-se 10 amostras do biofertilizante realizando-se, em seguida, análise química (Tabela 1), cujos teores de macro e micronutrientes foram determinados em extrato nitro-perclórico, obtido de acordo com metodologia proposta por Sarruge \& Haag (1974). O fósforo foi definido por colorimetria, pelo método vanadato fosfomolibdato (Malavolta et al., 1997) e o enxofre foi determinado por turbidimetria, conforme metodologia contida em Vitti (1989). Obtiveram-se os teores de nitrogênio total pelo método de Kjeldhal e os demais nutrientes por espectrofotometria de absorção atômica. $\mathrm{O}$ pH foi determinado em água, conforme metodologia descrita por Kiehl (1985). O carbono e a matéria orgânica o foram também pelo método Walkley-Black, descrito por Raij et al. (2001).

Para formulação das soluções nutritivas organo-minerais (SN1, SN2 e SN3) analisaram-se as concentrações dos nutrientes da solução nutritiva proposta por Castellane \& Araújo

Tabela 1. Concentração de elementos em grama por litro ( $\mathrm{g}$ $\left.\mathrm{L}^{-1}\right)$, relação $\mathrm{C} / \mathrm{N}$ (carbono/nitrogênio), matéria orgânica (\%) e $\mathrm{pH}$ do biofertilizante obtido do efluente de biodigestor

\begin{tabular}{cc}
\hline Elemento/Característica & Concentração/Valor \\
\hline $\mathrm{N}\left(\mathrm{g} \mathrm{L}^{-1}\right)$ & 1,5 \\
$\mathrm{P}\left(\mathrm{g} \mathrm{L}^{-1}\right)$ & 0,076 \\
$\mathrm{~K}\left(\mathrm{~g} \mathrm{~L}^{-1}\right)$ & 0,79 \\
$\mathrm{Ca}\left(\mathrm{g} \mathrm{L}^{-1}\right)$ & 0,05 \\
$\mathrm{Mg}\left(\mathrm{g} \mathrm{L}^{-1}\right)$ & 0,07 \\
$\mathrm{~S}\left(\mathrm{~g} \mathrm{~L}^{-1}\right)$ & 0,13 \\
$\mathrm{Fe}\left(\mathrm{g} \mathrm{L}^{-1}\right)$ & 0,01 \\
$\mathrm{Mn}\left(\mathrm{g} \mathrm{L}^{-1}\right)$ & 0,001 \\
$\mathrm{Cu}\left(\mathrm{g} \mathrm{L}^{-1}\right)$ & 0,0003 \\
$\mathrm{Zn}\left(\mathrm{g} \mathrm{L}^{-1}\right)$ & 0,0008 \\
$\mathrm{~B}\left(\mathrm{~g} \mathrm{~L}^{-1}\right)$ & 0,045 \\
$\mathrm{Mo}\left(\mathrm{g} \mathrm{L}^{-1}\right)$ & $\mathrm{ALD}$ \\
$\mathrm{Na}\left(\mathrm{g} \mathrm{L}^{-1}\right)$ & 0,08 \\
Relação C/N & $2 / 1$ \\
Matéria orgânica (\%) & 0,7 \\
$\mathrm{pH}$ & 8,0 \\
\hline ॠALD - Abaixo do limite de detecção &
\end{tabular}

R. Bras. Eng. Agríc. Ambiental, v.11, n.2, p.152-158, 2007.
(1994) para o meloeiro, confrontando-as com a análise obtida do biofertilizante. Em função desses dados, resolveu-se utilizá-lo como fonte de nitrogênio, balanceando-se as soluções nutritivas organo-minerais, em função deste nutriente, porém o biofertilizante, além de fornecer o nitrogênio, forneceria também outros nutrientes em quantidades variadas; desta forma, para se atender às necessidades nutricionais da cultura optou-se por se realizar a complementação mineral das soluções nutritivas organo-minerais, até que estas atingissem as mesmas concentrações de nutrientes (inclusive o nitrogênio) da solução nutritiva para o meloeiro utilizando-se, para tanto, de adubos minerais industrializados (sais hidrossolúveis); desta maneira, as 4 soluções nutritivas utilizadas na presente pesquisa, expostas na Tabela 2, deveriam apresentar as mesmas concentrações de nutrientes; entretanto, nas soluções organo-minerais (SN1, SN2 e SN3) ocorreu substituição de adubos minerais pelo biofertilizante.

Tabela 2. Quantidade dos compostos utilizados na composição de $1000 \mathrm{~L}$ das soluções nutritivas SN1 (100\% do nitrogênio proveniente do biofertilizante), SN2 (2/3 do nitrogênio oriundo do biofertilizante), SN3 (1/3 do nitrogênio originado do biofertilizante) e SN4 (composta somente por fertilizantes minerais hidrossolúveis).

\begin{tabular}{lcccc}
\hline & SN1 & SN2 & SN3 & SN4 \\
\hline Biofertilizante $(\mathrm{L})$ & 111,80 & 74,50 & 37,20 & - \\
\hline Nitrato de cálcio $(\mathrm{g})$ & - & 197,30 & 479,00 & 805,30 \\
\hline MAP $(\mathrm{g})$ & - & 159,30 & 172,80 & 186,25 \\
\hline Nitrato de potássio $(\mathrm{g})$ & - & 59,00 & 143,00 & 167,15 \\
\hline Cloreto de potássio $(\mathrm{g})$ & 182,40 & 274,00 & 272,00 & 294,30 \\
\hline Sulfato de magnésio $(\mathrm{g})$ & 168,00 & 200,00 & 237,00 & 246,00 \\
Sulfato de potássio $(\mathrm{g})$ & - & - & - & 22,00 \\
\hline Fosfato monopotássico $(\mathrm{g})$ & 139,10 & - & - & - \\
\hline Tenso Fe $(\mathrm{g})$ & 15,00 & 21,00 & 28,00 & 34,00 \\
\hline Profol* Cálcio $(\mathrm{mL})$ & 803,70 & 610,00 & 328,00 & - \\
\hline Profol Manganês $(\mathrm{mL})$ & 2,88 & 3,10 & 3,25 & 3,46 \\
\hline Profol Cobre $(\mathrm{mL})$ & - & - & 0,05 & 0,10 \\
\hline Profol Molibdênio $(\mathrm{mL})$ & - & - & - & 0,33 \\
\hline Profol Zinco $(\mathrm{mL})$ & 0,45 & 0,55 & 0,62 & 0,70 \\
Profol Boro $(\mathrm{mL})$ & - & - & - & 1,55 \\
\hline *Profol - produto comercial à base de cloreto, produzido pela Produquímica Ind. e Com. Ltda
\end{tabular}

Nota-se, na Tabela 3, que a quantidade de nutrientes provenientes do biofertilizante em substituição a fertilizantes hidrossolúveis, foi bastante significativa, chegando a $100 \%$ em alguns casos.

Realizaram-se medições semanais de condutividade elétrica (CE) e pH das soluções nutritivas e, também, coleta de 10 amostras de cada solução nutritiva, para realização de análises químicas, mantendo-se a mesma metodologia anteriormente descrita para análise do biofertilizante.

A cultura estudada foi o meloeiro (Cucumis melo L.) do grupo Cantalupe (rendilhado) híbrido Bonus 2.

Fez-se opção por um sistema de formação de mudas individuais em copos plásticos de $200 \mathrm{~mL}$ preenchidos com o substrato da marca Plantmax Hortaliças. Em outubro de 2003 realizou-se a semeadura com apenas 1 semente por copo, com 
Tabela 3. Porcentagem do total dos nutrientes presentes nas soluções nutritivas que tiveram, como fonte, o biofertilizante

\begin{tabular}{ccrrr}
\hline \multirow{2}{*}{ Nutriente } & \multicolumn{4}{c}{ Soluções Nutritivas } \\
\cline { 2 - 5 } & SN4 & \multicolumn{1}{c}{ SN3 } & SN2 & SN1 \\
N & 0 & 33,3 & 66,7 & 100,0 \\
P & 0 & 7,2 & 14,5 & 21,7 \\
K & 0 & 13,2 & 26,5 & 39,8 \\
Ca & 0 & 1,2 & 2,4 & 3,7 \\
Mg & 0 & 10,6 & 21,2 & 31,8 \\
S & 0 & 10,4 & 20,9 & 31,3 \\
Fe & 0 & 18,6 & 37,3 & 55,9 \\
Mn & 0 & 5,6 & 11,3 & 16,9 \\
Cu & 0 & 55,8 & 100,0 & 100,0 \\
Zn & 0 & 11,9 & 23,8 & 35,8 \\
\hline B & 0 & 100,0 & 100,0 & 100,0 \\
Mo & 0 & 0,0 & 0,0 & 0,0 \\
\hline
\end{tabular}

regas diárias com água, até que o substrato ficasse bem úmido. Desta maneira, as mudas se desenvolveram muito bem até a data do transplantio $(26 / 11 / 2003)$ aos 26 dias após a semeadura.

Utilizou-se o sistema hidropônico aberto, em que os 4 substratos estudados sustentaram as raízes das plantas e retiveram a solução nutritiva. Como recipientes de contenção utilizaram-se sacos de polietileno negro, com $10 \mathrm{~L}$ de substrato cada um, perfurados em sua parte inferior para escoamento do excesso de solução nutritiva; estes foram colocados a nível do solo, dentro da casa-de-vegetação, espaçados $0,5 \mathrm{~m}$ entre si e $1 \mathrm{~m}$ entre linhas, adotando-se o espaçamento de $0,5 \times 1,0 \mathrm{~m}$ ( 2 plantas $\left.\mathrm{m}^{-2}\right)$. A irrigação foi realizada através de gotejadores individuais da marca Carborundum, modelo GFT, com vazão de 2,5 $\mathrm{L} \mathrm{h}^{-1}$, a pressão de trabalho de $0,7 \mathrm{~atm}$, que aplicaram a solução nutritiva diretamente no substrato. Depois de alguns testes e observações, resolveu-se irrigar todos os tratamentos 2 vezes ao dia (às 9:00 e às 15:00 h) com as soluções nutritivas referentes a cada tratamento. A irrigação foi efetuada até que todos os substratos de cultivo atingissem a capacidade de campo, isto é, até que todos os sacos apresentassem escoamento da solução nutritiva nos orifícios abertos em sua parte inferior, seguindo recomendação de Milner (2002). As soluções drenadas, por sua vez, eram coletadas para medição da condutividade elétrica $(\mathrm{CE})$ e, quando uma delas atingia níveis críticos para a cultura do meloeiro que, segundo Andriolo (1999) é de 3,6 mS cm-1, irrigava-se apenas com água, até que a $\mathrm{CE}$ atingisse $2,0 \mathrm{mS} \mathrm{cm}^{-1}$, considerado limite inferior para a cultura do meloeiro, segundo Amor et al. (2001). Ressalta-se que em momento algum as plantas apresentaram sintomas visuais de deficiência hídrica, de falta de oxigenação, de deficiência mineral e/ou excesso de salinidade.

O experimento foi conduzido em casa-de-vegetação tipo capela com $3 \mathrm{~m}$ de pé direito, $51 \mathrm{~m}$ de comprimento, $10 \mathrm{~m}$ de largura, coberta com filme de polietileno de baixa densidade, com aditivo ultravioleta e espessura de $150 \mathrm{~mm}$; sua lateral foi protegida com telas de polipropileno com $30 \%$ de sombreamento e $1 \mathrm{~m}$ de altura.
Os tratos culturais necessários para a condução da cultura foram realizados segundo as recomendações de Goto \& Tivelli (1998), buscando-se sempre um ótimo desenvolvimento das plantas que foram conduzidas verticalmente com auxílio de fitilho (fita plástica). Na época do florescimento realizaram-se, para maior segurança, polinizações manuais diárias e o desbaste dos frutos, depois de constatados o pegamento e o desenvolvimento inicial ( $3 \mathrm{~cm}$ de diâmetro), deixando-se 3 frutos por planta.

Utilizou-se delineamento experimental em blocos casualisados, com 5 repetições e 16 tratamentos em um esquema fatorial 4 x 4 (4 substratos de cultivo e 4 soluções nutritivas). Ressalta-se que uma parcela experimental foi constituída por 4 plantas (4 sacos); portanto, o número total de plantas para este experimento foi de 4 (substratos) x 4 (soluções) x 5 (repetições) $\mathrm{x} 4$ (plantas por parcela) $=320$ plantas.

Com o intuito de avaliar o efeito dos tratamentos no crescimento vegetativo das plantas, aos 40, 44, 48 e 51 dias após a semeadura (DAS), mediram-se os comprimentos de todas as plantas de cada parcela (4 plantas por parcela); depois, objetivando-se avaliar o efeito dos tratamentos na precocidade da colheita dos frutos, realizaram-se colheitas semanais quando os frutos estavam maduros, anotando-se as respectivas datas e se calculando, em seguida, o tempo de colheita em dias após a semeadura (DAS); assim, obtida a produção total em cada tratamento, calculou-se a produtividade estimada em $\mathrm{kg} \mathrm{m}^{-2}$ para cada parcela. Para a obtenção do peso médio dos frutos, pesaram-se todos os frutos obtendo-se, em seguida, as médias.

As variáveis avaliadas foram submetidas a análise de variância e as médias comparadas pelo teste de Tukey a nível de $5 \%$ de probabilidade. Para melhor compreensão dos resultados, realizaram-se também regressões polinomiais para as variáveis produtividade e peso dos frutos.

\section{RESULTADOS E DISCUSSÃO}

Os valores apresentados na Tabela 4 permitem concluir-se que as soluções organo-minerais (SN1, SN2 e SN3) apresentaram valores mais altos de $\mathrm{pH}$ em relação à solução $100 \%$ mineral (SN4) podendo ser o fato explicado pela presença do biofertilizante na composição dessas soluções nutritivas. Pela análise química do biofertilizante, exposta na Tabela 1, tem-se que o $\mathrm{pH}$ deste material é 8,0 o que, certamente, aumentou os valores do $\mathrm{pH}$ das soluções nutritivas organo-minerais. Quanto à $\mathrm{CE}$, nota-se também que esta foi ligeiramente maior nas soluções nutritivas organo-minerais; esses maiores valores foram causados, sem dúvida, pela presença do biofertilizante que, além de conter nutrientes, continha também sódio (Tabela 1) e, provavelmente, sais ou compostos de origem desconhecida, aumentando a CE nas soluções organo-minerais. Pela análise química das soluções nutritivas (Tabela 4) percebe-se que houve variações na concentração dos elementos avaliados, explicáveis pela heterogeneidade do biofertilizante empregado que, por se tratar de um material de origem orgânica, apresenta variações em sua composição, porém de maneira geral, as variações não foram muito grandes, podendo- 
Tabela 4. Teores de nutrientes e sódio $\left(\mathrm{mg} \mathrm{L}^{-1}\right), \mathrm{pH}$ e CE $\left(\mathrm{mS} \mathrm{cm}^{-1}\right)$ encontrados nas soluções nutritivas estudadas

\begin{tabular}{crrrr}
\hline & SN1 & SN2 & SN3 & SN4 \\
N & 152,20 & 153,30 & 156,50 & 165,60 \\
$\mathrm{P}$ & 31,00 & 35,50 & 41,00 & 41,50 \\
$\mathrm{~K}$ & 298,50 & 281,50 & 263,50 & 225,00 \\
$\mathrm{Ca}$ & 134,00 & 142,50 & 159,00 & 152,50 \\
$\mathrm{Mg}$ & 30,00 & 28,50 & 28,00 & 21,50 \\
$\mathrm{~S}$ & 71,50 & 68,50 & 65,50 & 56,00 \\
$\mathrm{Fe}$ & 1,40 & 1,35 & 1,55 & 1,4 \\
$\mathrm{Mn}$ & 0,40 & 0,25 & 0,40 & 0,65 \\
$\mathrm{Cu}$ & 0,35 & 0,50 & 0,25 & 0,20 \\
$\mathrm{Zn}$ & 0,40 & 0,30 & 0,30 & 0,35 \\
$\mathrm{~B}$ & 0,65 & 0,45 & 0,30 & 0,30 \\
$\mathrm{Na}$ & 13,00 & 10,5 & 9,5 & 8,00 \\
$\mathrm{pH}$ & 7,55 & 7,30 & 6,50 & 6,20 \\
$\mathrm{CE}$ & 2,25 & 2,35 & 2,30 & 2,10 \\
\hline
\end{tabular}

se afirmar que a metodologia utilizada na complementação mineral das soluções nutritivas foi adequada.

Verifica-se, na Tabela 5, que em todas as épocas de amostragem o comprimento das plantas cultivadas com os substratos S1, S2 e S3, que continham o efluente em sua mistura, superou as cultivadas no substrato S4 (100\% areia). Este fato é explicado por Villela Júnior (2005) que verificou que a adição de efluente de biodigestor seco e moído à areia, proporcionou melhorias físico-químicas ao substrato de cultivo e melhores condições para a planta se desenvolver.

Em nenhuma data houve diferença significativa entre os comprimentos das plantas cultivadas com as 4 soluções nutritivas estudadas, resultado que demonstra que a utilização do biofertilizante nas soluções nutritivas, em substituição aos adubos convencionais, não alterou nem modificou o cresci-

Tabela 5. Comprimento das plantas $(\mathrm{cm})$ do meloeiro Bonus 2, aos 40, 44, 48 e 51 dias após a semeadura (DAS) cultivadas com os substratos e as soluções nutritivas estudadas

\begin{tabular}{|c|c|c|c|c|}
\hline & 40 DAS & 44 DAS & 48 DAS & 51 DAS \\
\hline \multicolumn{5}{|l|}{ Substratos (S) } \\
\hline S1 & $74,15 A^{1}$ & $117,46 \mathrm{~A}$ & $160,40 \mathrm{~A}$ & $194,23 \mathrm{~A}$ \\
\hline S2 & $72,61 \mathrm{~A}$ & $117,13 \mathrm{~A}$ & $161,03 \mathrm{~A}$ & $195,68 \mathrm{~A}$ \\
\hline S3 & $71,06 \mathrm{~A}$ & $114,45 \mathrm{~A}$ & $152,55 \mathrm{~A}$ & $191,53 \mathrm{~A}$ \\
\hline S4 & $48,99 \mathrm{~B}$ & $78,71 \mathrm{~B}$ & $120,43 \mathrm{~B}$ & $145,63 \mathrm{~B}$ \\
\hline Teste F para substratos (S) & 42,86 ** & $58,49 * \star$ & 26,32 ** & 66,74 ** \\
\hline \multicolumn{5}{|l|}{ Soluções Nutritivas (SN) } \\
\hline SN1 & $66,37 \mathrm{~A}$ & $104,79 \mathrm{~A}$ & $145,57 \mathrm{~A}$ & $178,10 \mathrm{~A}$ \\
\hline SN2 & $65,84 \mathrm{~A}$ & $106,39 \mathrm{~A}$ & $151,18 \mathrm{~A}$ & $182,75 \mathrm{~A}$ \\
\hline SN3 & $66,86 \mathrm{~A}$ & $107,63 \mathrm{~A}$ & $147,28 \mathrm{~A}$ & $182,13 \mathrm{~A}$ \\
\hline SN4 & $67,74 \mathrm{~A}$ & $108,95 \mathrm{~A}$ & $150,28 \mathrm{~A}$ & $184,08 \mathrm{~A}$ \\
\hline $\begin{array}{l}\text { Teste F para soluções } \\
\text { nutritivas (SN) }\end{array}$ & $0,20^{\mathrm{ns}}$ & $0,52^{\mathrm{ns}}$ & $0,49^{n s}$ & $0,76^{\text {ns }}$ \\
\hline Teste F para Interação S x N & $0,60^{\mathrm{ns}}$ & 1,09 ns & 1,09 ns & $1,00^{\mathrm{ns}}$ \\
\hline Teste F para blocos & $0,23^{\mathrm{ns}}$ & $0,79^{\mathrm{ns}}$ & $0,74^{\mathrm{ns}}$ & $0,34^{\mathrm{ns}}$ \\
\hline DMS $(5 \%)$ & 6,79 & 9,23 & 13,98 & 11,06 \\
\hline CV (\%) & 12,16 & 10,32 & 11,25 & 7,28 \\
\hline
\end{tabular}

${ }^{1}$ Valores seguidos das mesmas letras nas colunas não diferem entre si pelo teste de Tukey a $5 \%$ de probabilidade

** Significativo em nível de $1 \%$ de probabilidade; ns Não significativo em nível de $5 \%$ mento vegetativo das plantas de meloeiro, sugerindo que a metodologia utilizada na complementação mineral das soluções nutritivas foi bem sucedida, podendo-se supor que o biofertilizante produzido a partir de efluente de biodigestor pode substituir adubos minerais hidrossolúveis no cultivo hidropônico em substratos, concordando com os resultados obtidos por Villela Júnior et al. (2003).

Verifica-se, na Tabela 6, um tempo de colheita menor dos frutos produzidos pelas plantas cultivadas com os substratos S1, S2 e S3, que continham o efluente; este fato ocorreu devido, certamente, ao crescimento vegetativo mais rápido observado nesses tratamentos (Tabela 5), o que ocasionou, sem dúvida, maior precocidade na colheita dos frutos.

No que se refere às soluções nutritivas estudadas, não se observaram diferenças significativas no tempo de colheita dos frutos, resultado que permite dizer que a substituição de adubos minerais hidrossolúveis pelo biofertilizante estudado não alterou nem atrasou o ciclo da cultura, embora tenha ocorrido diferenças significativas no peso dos frutos e na produtividade estimada, seja para os substratos ou para as soluções nutritivas estudadas (Tabela 6).

Os dados da variável produtividade foram submetidos a análise de regressão polinomial, a qual constatou efeito quadrático significativo a $5 \%$ de probabilidade em função da porcentagem de efluente seco e moído que continha o substrato de cultivo (Figura 1).

A regressão apresentada na Figura 1, mostra que a produtividade máxima alcançada foi de $8039,07 \mathrm{~g} \mathrm{~m}^{-2}$, quando o

Tabela 6. Tempo de colheita dos frutos em dias após a semeadura (DAS), peso dos frutos (g) e produtividade estimada $\left(\mathrm{g} \mathrm{m}^{-2}\right)$ do meloeiro Bonus 2, cultivado com os substratos e as soluções nutritivas estudados

\begin{tabular}{|c|c|c|c|}
\hline & $\begin{array}{l}\text { Tempo de } \\
\text { Colheita dos } \\
\text { frutos (dias) }\end{array}$ & $\begin{array}{l}\text { Peso dos } \\
\text { Frutos } \\
\text { (g) }\end{array}$ & $\begin{array}{l}\text { Produtividade } \\
\text { Estimada } \\
\left(\mathrm{g} \mathrm{m}^{-2}\right)\end{array}$ \\
\hline \multicolumn{4}{|l|}{ Substratos (S) } \\
\hline S1 & $95,10 \mathrm{~B}^{1}$ & $1329,84 \mathrm{~A}$ & $8001,67 \mathrm{~A}$ \\
\hline S2 & $96,07 \mathrm{~B}$ & $1329,20 \mathrm{~A}$ & $8003,16 \mathrm{~A}$ \\
\hline S3 & $95,91 \mathrm{~B}$ & $1282,86 \mathrm{~A}$ & $7697,19 \mathrm{~A}$ \\
\hline S4 & $98,58 \mathrm{~A}$ & $1183,01 \mathrm{~B}$ & $7098,03 \mathrm{~B}$ \\
\hline Teste F para substratos (S) & 8,20 ** & $11,89 * \star$ & $12,51 * \star$ \\
\hline \multicolumn{4}{|l|}{ Soluções Nutritivas (SN) } \\
\hline SN1 & $96,06 \mathrm{~A}$ & $1239,91 \mathrm{~B}$ & 7439,47 B \\
\hline SN2 & $96,76 \mathrm{~A}$ & $1272,81 \mathrm{AB}$ & $7664,79 \mathrm{AB}$ \\
\hline SN3 & $96,53 \mathrm{~A}$ & $1289,94 \mathrm{AB}$ & $7747,44 \mathrm{AB}$ \\
\hline SN4 & $96,31 \mathrm{~A}$ & $1322,25 \mathrm{~A}$ & $7948,36 \mathrm{~A}$ \\
\hline $\begin{array}{l}\text { Teste F para soluções } \\
\text { nutritivas (SN) }\end{array}$ & $0,32^{\text {ns }}$ & 2,94 * & 3,05 * \\
\hline $\begin{array}{l}\text { Teste F para } \\
\text { Interação S x N }\end{array}$ & $1,31^{\text {ns }}$ & $1,00^{\mathrm{ns}}$ & $1,01^{\mathrm{ns}}$ \\
\hline Teste F para blocos & $0,89^{\mathrm{ns}}$ & $1,00^{\mathrm{ns}}$ & $0,69^{\mathrm{ns}}$ \\
\hline DMS (5\%) & 1,97 & 74,92 & 450,89 \\
\hline CV (\%) & 2,44 & 6,99 & 7,00 \\
\hline
\end{tabular}

Valores seguidos das mesmas letras nas colunas não diferem entre si pelo teste de Tukey a $5 \%$ de probabilidade

** Significativo em nível de $1 \%$ de probabilidade; * Significativo em nível de $5 \%$ de probabilidade; ns Não significativo em nível de $5 \%$ 


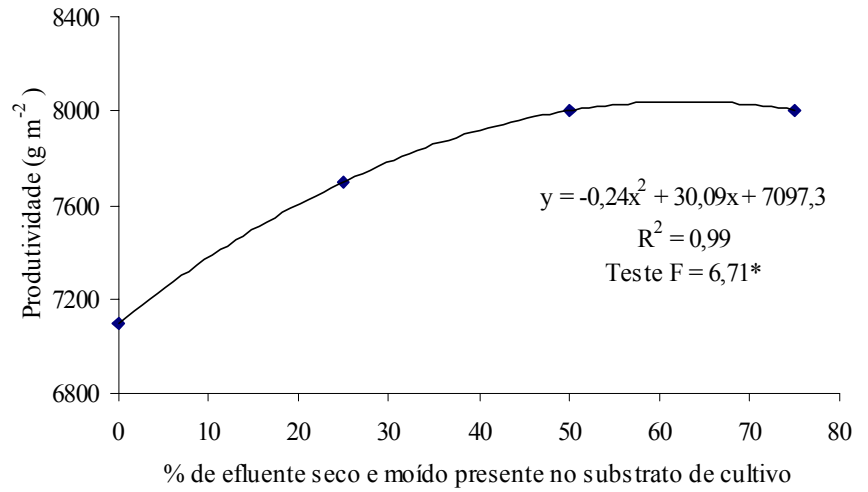

* Significativo a nível de $5 \%$ de probabilidade

Figura 1. Variação da produtividade do meloeiro em função da porcentagem de efluente seco e moído presente no substrato de cultivo

substrato apresentava $62,6 \%$ de efluente na sua composição; este resultado reforça a idéia de que a mistura do efluente à areia melhorou as características físico-químicas do substrato, conduzindo a cultura do meloeiro a melhores rendimentos, concordando com as observações de Abad \& Nogueira (1998), que recomendam a mistura entre materiais de origem orgânica e materiais de origem mineral, com o que a utilização de efluente de biodigestor como substrato de cultivo, além de contribuir para a busca da sustentabilidade em uma propriedade agrícola, pode proporcionar ganhos de produtividade ao produtor. Todos os substratos testados (Tabela 6) superaram a máxima produtividade obtida por Cecílio Filho et al. (2003), de $6133 \mathrm{~g} \mathrm{~m}^{-2}$, que cultivaram o meloeiro Bonus 2 em substrato de quartzo moído. Os frutos também foram mais pesados que os obtidos por Gusmão et al. (2003) que, cultivando o híbrido Bonus 2 em substrato areia, obtiveram frutos com 830,3 g, em média.

Percebe-se, pela regressão polinomial representada pela Figura 2, que a variável produtividade apresentou efeito linear significativo a $1 \%$ de probabilidade em função da quantidade de biofertilizante utilizada na composição das soluções nutritivas estudadas.

A Figura 2 revela que a produtividade máxima alcançada foi de 7941,4 $\mathrm{g} \mathrm{m}^{-2}$, fato verificado quando a solução nutritiva não continha o biofertilizante, isto é, quando se utilizou a solução $100 \%$ mineral, porém a Tabela 6 mostra que, quando

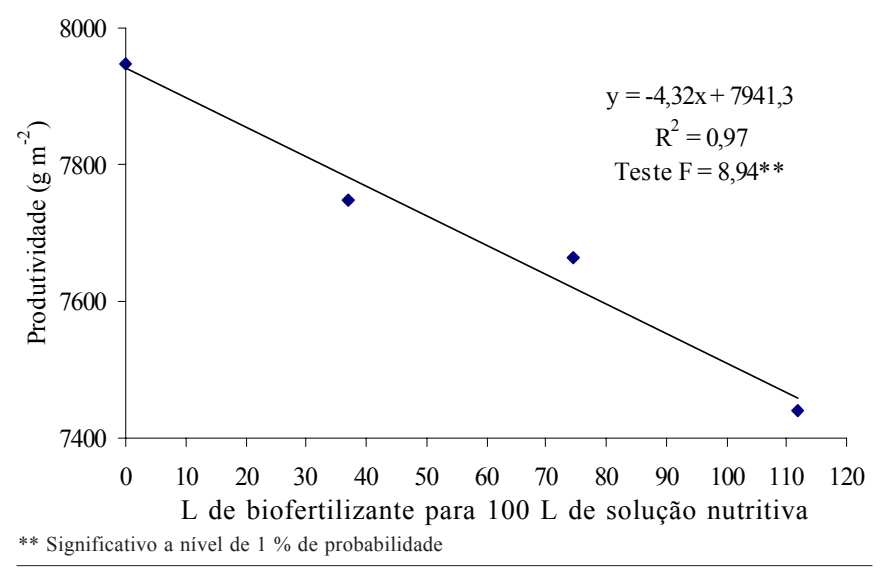

Figura 2. Variação da produtividade do meloeiro em função da quantidade de biofertilizante (L) utilizado na composição de $1000 \mathrm{~L}$ de solução nutritiva se utilizaram 74,5 e 37,2 L de biofertilizante nas soluções nutritivas (respectivamente SN3 e SN2), a produtividade não se diferenciou estatisticamente quando do uso da solução nutritiva 100\% mineral (SN4). Referidos resultados sugerem que o biofertilizante estudado pode substituir parcialmente adubos hidrossolúveis no cultivo de plantas em substratos, concordando com os resultados obtidos por Villela Júnior et al. (2003). As produtividades médias alcançadas com as soluções nutritivas organo-minerais SN1, SN2 e SN3 de 7439,47; 7664,79 e 7747,44 $\mathrm{g} \mathrm{m}^{-2}$, respectivamente, foram superiores à alcançada por Andriolo et al. (2003) de 4715,00 $\mathrm{g} \mathrm{m}^{-2}$; esses autores cultivaram o meloeiro em substrato comercial orgânico utilizando a mesma solução nutritiva de Castellane \& Araújo (1994) testada na presente pesquisa e somente adubos minerais hidrossolúveis. Este fato demonstra que a substituição parcial de adubos minerais industrializados pelo biofertilizante proporcionou produtividades consideradas boas, podendo ser uma alternativa viável ao produtor, concordando com Villela Junior et al. (2003).

\section{CONCLUSÕES}

1. A mistura do efluente de biodigestor seco e moído à areia na composição dos substratos de cultivo proporcionou crescimento vegetativo mais rápido ao meloeiro.

2. A substituição de adubos minerais hidrossolúveis pelo biofertilizante proveniente da biodigestão de estrume bovino não alterou o crescimento vegetativo do meloeiro.

3. A adição do efluente de biodigestor seco e moído à areia na composição dos substratos de cultivo proporcionou maior precocidade na colheita, frutos maiores e maior produtividade à cultura do meloeiro.

4. Adubos minerais hidrossolúveis utilizados no cultivo de plantas em substrato podem ser parcialmente substituídos pelo biofertilizante proveniente da biodigestão de estrume bovino.

\section{AGRADECIMENTOS}

Os autores agradecem à CAPES, pela concessão de bolsa em nível de doutorado, e à FAPESP, pelos recursos de auxílio à pesquisa, concedidos (Processo $N^{\circ}$ 02/08387-7), tornando possível a realização deste trabalho científico.

\section{LITERATURA CITADA}

Abad, B.M.; Nogueira, M.P. Substratos para el cultivo sin suelo y fertirrigacion. In: Cadahia, C. Fertirrigacion: Cultivos hortícolas y ornamentales. Madrid: Mundi-Prensa, 1998. p.287-339.

Amor , F.M.; Flores, P.; Carvajal, M.; Martínez, J.M.; Navarro, J.M.; Cerdá, A. Yield responses of soilless melon and tomato to different irrigation water qualities. Acta Horticulturae, Wageningen, n.559, p.333-338, 2001. 
Andrilolo, J.L. Fisiologia das culturas protegidas. Santa Maria: UFSM, 1999. 142p.

Andriolo, J.L.; Lanzanova, M.E.; Witter, M. Produtividade de frutos de meloeiro cultivado em substrato com três soluções nutritivas. Horticultura Brasileira, Brasília, v.21, n.3, p.478-481, 2003.

Chaves, H.J. Apuntes del proyecto "Xochicalli"; casa ecológica autosuficiente. Texcoco: Universidad Autónoma Chapingo, 1977. 25p. Mimeografado

Chaves, H.J. Digestión anaeróbica de desechos orgánicos. Texcoco: Universidad Autónoma Chapingo, 1981. 45p. Mimeografado

Castellane, P.D.; Araújo, J.A.C. de. Cultivo sem solo: Hidroponia. Jaboticabal: FUNEP, 1994. 43p.

Cecílio Filho, A.B.; May, A.; Branco, R.B.F.; Braz, L.T.; Peixoto, J.R. Production and quality of melons grown in two different substrates under soilless cultivation. Acta Horticulturae, Wageningen, n.607, p.163-168, 2003.

Fries, M.R.; Aita, C. Aplicação de esterco de bovino e efluente de biodigestor em um solo Podzólico Vermelho-Amarelo: efeito sobre a produção de matéria seca e absorção de nitrogênio pela cultura do sorgo. Revista do Centro de Ciências Rurais, Santa Maria, v.20, n.1-2, p.137-145, 1990.

Goto, R.; Tivelli, S.W. Produção de hortaliças em ambiente protegido: condições subtropicais. São Paulo: UNESP, 1998. 319p. Coleção Agronomia

Gusmão, M.T.A. de; Gusmão, S.A.L. de; Baracioli, F.Z.; Factor, T.L.; Araújo, J.A.C. de. Yield and quality of net melon cultivated on sand in the greenhouse. Acta Horticulturae, Wageningen, n.607, p.143-147. 2003.

Kämpf, A.N. Seleção de materiais para uso como substrato. In: Encontro Nacional sobre Substratos para Plantas, 1, 2000, Porto Alegre. Anais... Porto Alegre: Gênesis, 2000. p.139146.

Kiehl, E.J. Fertilizantes orgânicos. Piracicaba: Agronômica Ceres, 1985, 492p.
Malavolta, E.; Vitti, G.C.; Oliveira, S.A. Avaliação do estado nutricional das plantas: princípios e aplicações. 2.ed. Piracicaba: Potafós, 1997. 319p.

Mavrogianopoulos, G.; Vogli, V.; Kyritsis, S. Use of wastewater as a nutrient solution in a closed gravel hydroponic culture of giant reed (Arundo donax). Bioresourse Technology, Essex, v.82, n.2, p.103-107, 2002.

Menezes Jr., F. O. G. de.; Martins, S.R.; Fernandes, H.S. Crescimento e avaliação nutricional da alface cultivada em "NFT" com soluções nutritivas de origem química e orgânica. Horticultura Brasileira, Brasília, v.22, n.3, p.632-637, 2004.

Milner, L. Manejo de irrigação e fertirrigação em substratos. In: Furlani, A.M.C.; Bataglia, O.C.; Abreu, M.F. de; Abreu, C.A. de; Furlani, P.R.; Quaggio, J.A.; Minami, K. Caracterização, manejo e qualidade de substratos para produção de plantas. Campinas: IAC, 2002. Documentos, 70

Nikmane, M.A.; Klintsare, A.Y; Beker, M.E. Production of a green feed by the hydroponic method using fermented pig manure. Mikrobiologiva i Biotekhnologiva Proizvodstva Kormov, Zinatine, v.1, p.134-144, 1990.

Raij, B. van; Andrade, J.C.; Cantarella, H.; Quaggio, J.A. Análise química para avaliação da fertilidade do solo. Campinas: IAC, 2001. 285p.

Sarruge, J.R.; Haag, H.P. Análises químicas em plantas. Piracicaba: ESALQ/USP, 1974. 56p.

Villela Jr., L.V.E. Utilização de efluente de biodigestor como substrato e solução nutritiva para o cultivo do meloeiro. Jaboticabal: UNESP, 2005. 98p. Tese Doutorado

Villela Jr., L.V.E.; Araujo, J.A.C.; Factor, T.L. Efeito da utilização do efluente de biodigestor no cultivo hidropônico do meloeiro. Revista Brasileira de Engenharia Agrícola e Ambiental, Campina Grande, v.7, n.1, p.72-79, 2003.

Vitti, G.C. Avaliação e interpretação de enxofre no solo e na planta. Jaboticabal: FUNEP, 1989. 37p.

Volpe, C.A.; Minchio, C.A.; Barbosa, J.C.; André, R.B. Análise da precipitação mensal em Jaboticabal (SP). Ciência Agronômica, Jaboticabal, v.4, n.2, p.3-5, 1989. 